\title{
PENINGKATAN KETAHANAN PANAS MATERIAL PISTON DENGAN PELAPISAN HA
}

\author{
Devout Prakoso Trismianto ${ }^{1}$
}

\begin{abstract}
ABSTRAK
Keausan pada piston dikarenakan kondisi kerja piston yang bekerja menahan suhu yang tinggi, tekanan yang besar dan gaya gesek secara terus menerus dalam jangka waktu yang lama,sehingga piston mengalami keausan. Salah satu upaya untuk memperkuat piston yang dilakukan yaitu dengan pelapisan Thermal Barrier Coating. Teknik pelapisan dengan metode thermal barrier coating banyak digunakan didunia penerbangan khususnya untuk pembuatan turbin. Pada penelitian ini, hydroxyapatite telah berhasil dilapiskan pada permukaan substrat piston menggunakan metode thermal barrier coating dengan alat flame spray. Penelitian ini bertujuan untuk meningkatkan ketahanan terhadap thermal dengan melakukan pelapisan hydroxyapatite (HA) yang menggunakan metode flame spray dengan variasi tekanan gas oksigen. Variasi tekanan gas oksigen yang digunakan adalah 4 bar, 5 bar, 6 bar. Untuk melihat karakteristik dan sifat mekanik dilakukan pengujian Scanning electron microscope (SEM) untuk melihat struktur permukaan lapisan, mikroskop makro untuk melihat penampang samping, uji kerekatan untuk mengetahui tingkat kerekatan lapisan dan uji konduktifitas thermal untuk mengetahui sejauh mana lapisan mampu menahan suhu. Hasil pengujian menunjukkan pelapisan dengan tekanan gas oksigen 6 bar mempunyai struktur mikro yang lebih homogen, tidak terlihat porous, difusi secara merata, memiliki nilai kerekatan yang lebih baik yaitu 4B dengan presentase $4 \%$ dan sedangkan untuk uji konduktivitas thermal bahan, didapat nilai konduktivitas thermal dari hydroxyapatite sebesar, $\mathrm{K}_{\mathrm{HA}}=0,295 \mathrm{cal} / \mathrm{msK}$.
\end{abstract}

Kata kunci : Pelapisan, Ketahanan Panas, Coating, Konduktivitas Thermal.

\section{PENDAHULUAN}

Penggunaan alumunium pada industri otomotif terus meningkat sejak tahun 1980. Banyak komponen otomotif yang terbuat dari paduan alumunium, diantaranya piston, blok mesin, cylinder head, valve dan lain sebagainya. Salah satu kasus kerusakan pada suku cadang yang sering ditemui pada alat transportasi selama ini adalah keausan piston. Keausan pada piston dikarenakan kondisi kerja piston yang bekerja menahan suhu yang tinggi, tekanan yang besar dan gaya gesek secara terus menerus dalam jangka waktu yang lama, sehingga piston mengalami keausan (Budinski,2001). Hal inilah yang menyebabkan komponen piston perlu dilakukan penggantian dalam jangka waktu tertentu sesuai dengan penggunaan.

\footnotetext{
${ }^{1}$ Program Studi Teknik Mesin Fakultas Teknik, Universitas Muhammadiyah Semarang
} 


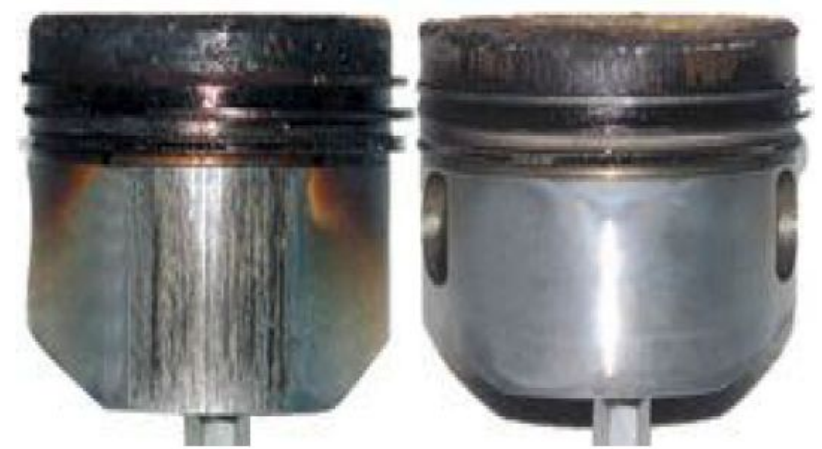

Gambar 1. Kerusakan piston karena aus (www.jepistons.com)

Faktor penyebab rusaknya piston yaitu keausan material, bahwa material yang digunakan kurang mampu menahan suhu yang tinggi, gesekan, serta tekanan yang besar. Salah satu upaya untuk memperkuat piston yang dilakukan yaitu dengan pelapisan Thermal Barrier Coating. Lapisan keramik sering digunakan untuk memberikan perbaikan pada keausan, korosi, erosi, dan panas dalam desain. Meskipun pelapis menunjukkan ketidakpastian dan variabilitas yang berlebihan, Thermal Barrier Coating (TBCS) pada mesin pembakaran dalam ruangan masih menjadi bahan penelitian terutama untuk mengurangi penolakan panas di silinder pada mesin adiabatik. TBC biasanya digunakan pada substrat piston untuk melindungi mereka secara termal agar suhu operasi lebih tinggi. TBC juga bisa digunakan dalam isolasi komponen ruang bakar pada mesin Low Heat Rejection (LHR) yang dapat mengurangi perpindahan panas antara campuran bahan bakar gas di dalam silinder dan dinding silinder sehingga meningkatkan suhu pembakaran. Konsep mesin LHR didasarkan pada pengurangan penolakan panas terhadap pendingin dan pemulihan energi dalam bentuk pekerjaan yang bermanfaat (Manohar B, 2015).

Salah satu metode pelapisan yang telah diterima dengan baik di kalangan industri adalah pelapisan berbasis thermal spray coating karena kemudahannya untuk diaplikasikan pada pelapisan material dalam skala besar. Dewasa ini, teknologi thermal spray telah digunakan secara intensif sebagai thermal barrier coatings untuk industri dirgantara (aerospace), komponen boiler serta komponen automotif. Thermal spray merupakan gabungan dari beberapa proses dimana prinsip kerjanya adalah suatu material (dalam bentuk wire, rod atau powder) dipanaskan oleh sumber panas (flame atau arc) setelah material meleleh langsung ditekan oleh udara tekan sehingga menempel pada permukaan benda kerja membentuk lapisan baru (Lusiani dkk, 2013).

Pada penelitian yang sudah dilakukan, untuk metode thermal spray untuk proses pelapisan pada baja $\mathrm{AISI} 4140$ dengan serbuk lapisan paduan antara $\mathrm{FeCrBMnSi}$ dan $\mathrm{Ni}-\mathrm{Al}$ 
penggunaan tekanan gas pada 6 bar menghasilkan sifat mekanik yang lebih baik dibandingkan variabel tekanan dibawahnya (Pratama P.D, 2017). Berdasarkan hasil tersebut penulis menggunakan variabel 4 bar, 5 bar, dan 6 bar pada penelitian ini dengan metode lain yaitu flame spray pada material piston Daihatsu Hijet 1000 dengan menggunakan serbuk lapisan hydroxyapatite. Dengan referensi sebelumnya diharapkan penulis mendapatkan variabel tekanan gas oksigen yang tepat sehingga menghasilkan hasil pelapisan yang optimal.

\section{METODE PENELITIAN}

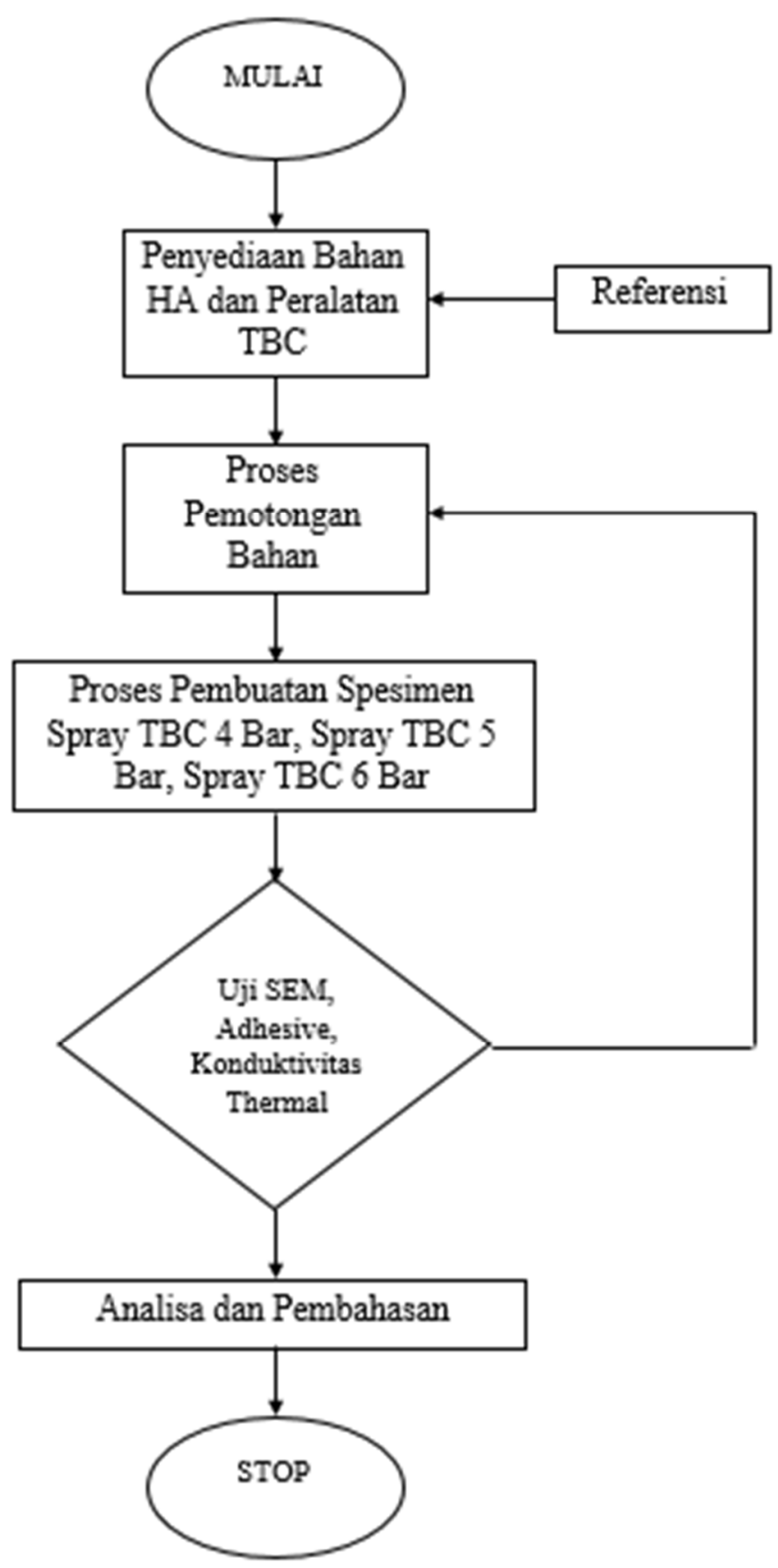

Gambar 2. Diagram Alur Penelitian 


\section{HASIL DAN PEMBAHASAN}

\section{Uji SEM}

Pengujian scanning electron microscope (SEM) untuk mengetahui struktur morfologi dari hydroxyapatite yang dilapis pada piston. Pengujian ini dengan sampel potongan piston yang dilapisi hydroxyapatite. Hasil dari piston yang dilapisi dengan hydroxyapatite dipilih bagian yang merata penuh dan dipotong dengan ukuran maksimum 8 x $8 \mathrm{~mm}$. Dilakukan pemtongan dengan ukuran ini dimaksudkan untuk menyesuaikan dengan peralatan uji scanning electron microscope agar dapat diambil datanya. Pengujian scanning electron microscope dilakukan dengan 3 potongan spesimen antara lain : pelapisan pada tekanan oksigen 4 Bar, 5 Bar, dan 6 Bar. Hasil uji SEM dapat diketahui pada Gambar 3.
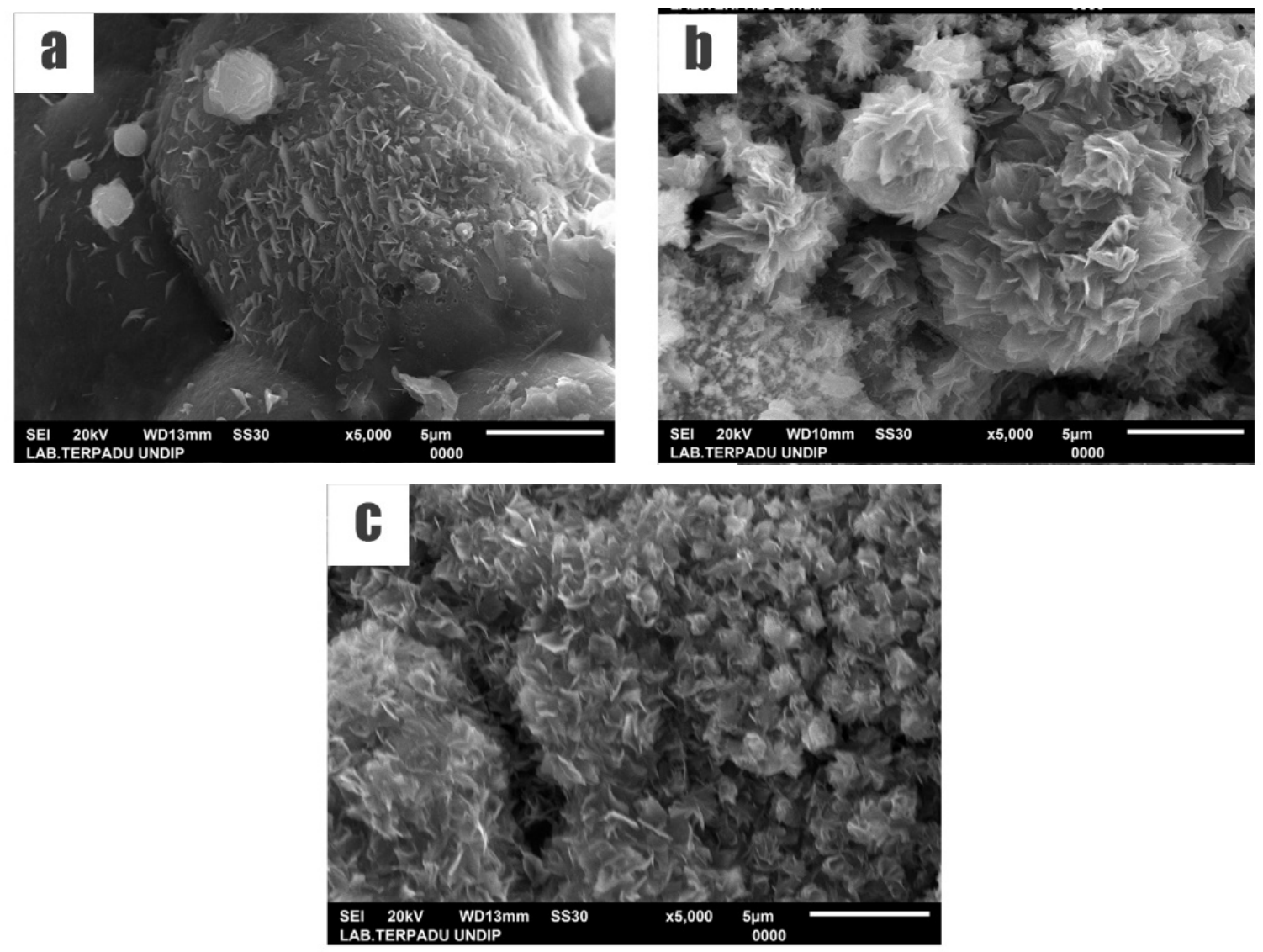

Gambar 3. Hasil Uji Sem

$$
\text { (A) } 4 \text { Bar (B) } 5 \text { Bar (C) } 6 \text { Bar }
$$

Hasil uji scanning electron microscope pada permukaan pelapisan ketiga spesimen yang ditunjukkan Gambar 3 dengan pembesaran 5000x. Dimana didapat perbedaan struktur permukaan pada ketiga spesimen. 
Pada hasil uji scanning electron microscope dengan meningkatnya tekanan gas oksigen yang digunakan maka butiran - butiran yang terdapat di permukaan substrat mampu menyatu. Hal ini disebabkan oleh meningkatnya kecepatan impact dari menyatunya butiran yang lebih kecil ke permukaan substrat seiring dengan meningkatnya tekanan gas oksigen yang digunakan. Sehingga mampu meminimalisir rongga yang terbentuk antara butiran-butiran tersebut.

\section{Uji Struktur Makro}

Pengujian dengan menggunakan mikroskop makro dimaksudkan untuk melihat struktur makro interface antar muka apakah terjadi difusi atau tidak hasil dari pelapisan yang dilakukan. Pengujian dilakukan pada sisi samping pelapisan sehingga dapat dilihat substrat dan pelapisannya dengan pembesaran 50 kali seperti pada Gambar 4.
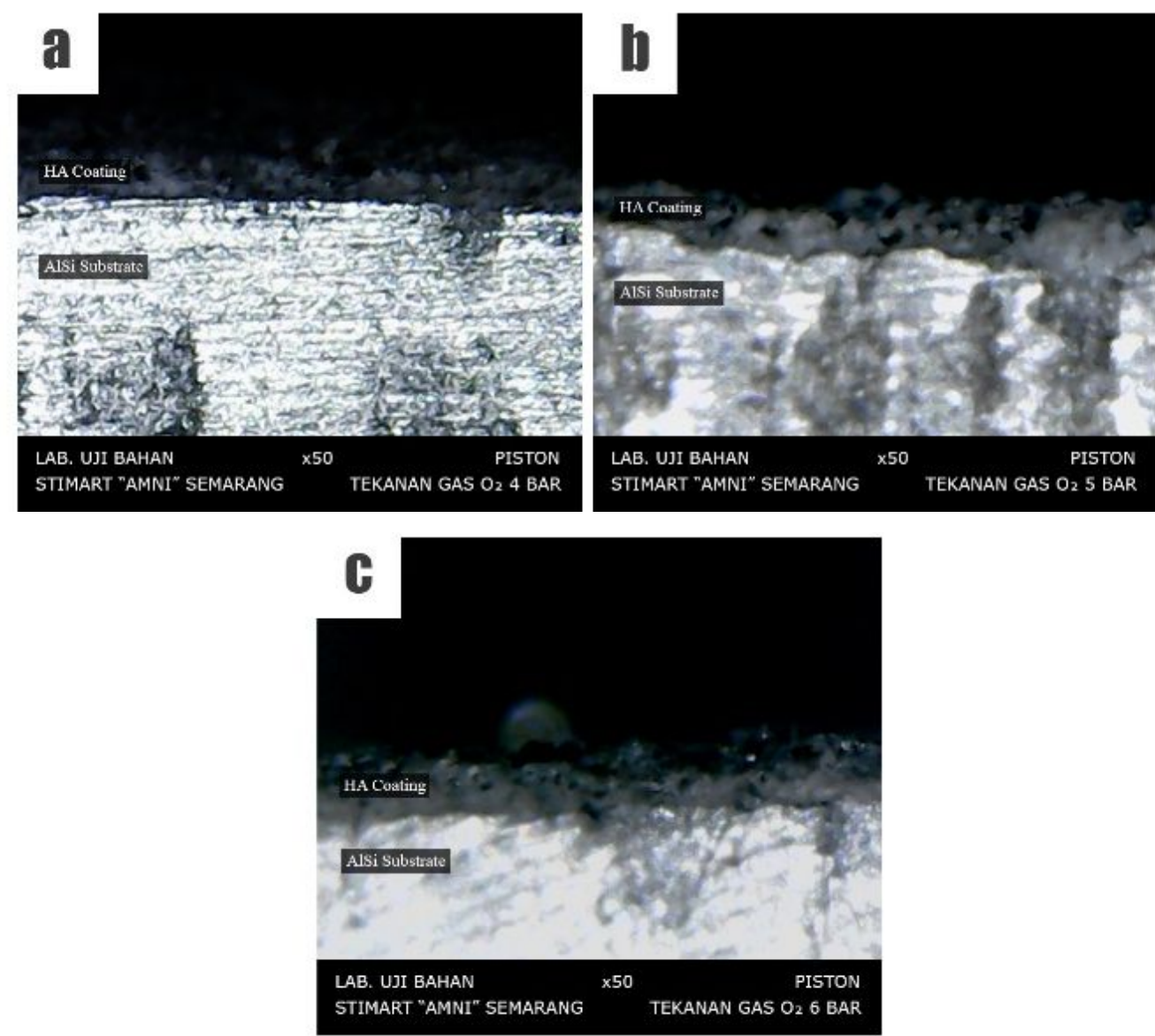

Gambar 4. Hasil Uji Struktur Makro

$$
\text { (A) } 4 \text { Bar (B) } 5 \text { Bar (C) } 6 \text { Bar }
$$


Hasil uji struktur makro dari sisi samping yang ditunjukan pada Gambar 4 dengan pembesaran 50x .Hasil uji dari sisi samping ini dapat diketahui lapisan terjadi proses difusi atau hanya menempel tanpa adanya difusi lapisan. Pengembangan sistem thermal barier coating modern saat ini, menitik beratkan pada bagaimana menghasilkan lapisan bond coat yang mampu membentuk lapisan protektif secara alami, kontinu dan perlahan (slow growing) dengan ketebalan tertentu, seragam dan memiliki daya ikat yang optimal guna menghindari terjadinya kegagalan dini (spallation) (Heuer A. H., dkk., 2006).

Pelapisan menghasilkan pencapaian adhesi yang baik apabila pelapis masuk ke substrat (Chen dkk, 2005). Dari hasil pelapisan pada lapisan dengan tekanan oksigen 4 Bar, titik - titik yang terjadi difusi atau pelapis hydroxyapatite yang masuk ke substrat tidak merata hal ini disebabkan pori-pori permukaan piston belum sepenuhnya terbuka. Pada tekanan oksigen 5 Bar permukaan piston mulai terbuka dengan baik sehingga terjadi difusi, hal ini disebabkan ketika ukuran butir yang keluar dari flame spray mampu menyatu dengan baik secara merata hasilnya lapisan dapat masuk ke substrat yang lebih dulu dipanasi untuk membuka pori - pori. Serbuk yang meleleh dan masuk ke dalam substrat membentuk difusi lapisan untuk mengikat pelapis dengan substrat. Pada spesimen kedua dan ketiga difusi cukup merata namun pada spesimen ketiga struktur atas terbentuk lebih baik. Penyebabnya pada saat proses penyemprotan dengan tekanan 6 Bar pori-pori permukaan piston terbuka lebih besar sehingga difusi terjadi lebih baik. Pada ketiga spesimen tidak terjadi void - void dalam substrat hal ini ditunjukkan pada gambar ketiga spesimen diatas hanya terjadi difusi lapisan dengan kedalaman yang tidak terlalu besar. Terjadi void apabila serbuk hydroxyapatite masuk kedalam piston dengan bentuk bintik - bintik.

\section{Uji Kerekatan}

Pengujian kerekatan menggunakan standar ASTM D 3395-09, dilakukan pengujian kerekatan untuk mengetahui sejauh mana kemampuan hydroxyapatite yang menempel pada permukaan piston. Pengujian kerekatan dilakukan pada 3 spesimen, yaitu, pelapisan pada tekanan gas oksigen 4, 5, dan 6 Bar. Hasil pengujian kerekatan dapat diketahui seperti pada

\section{Gambar 5.}



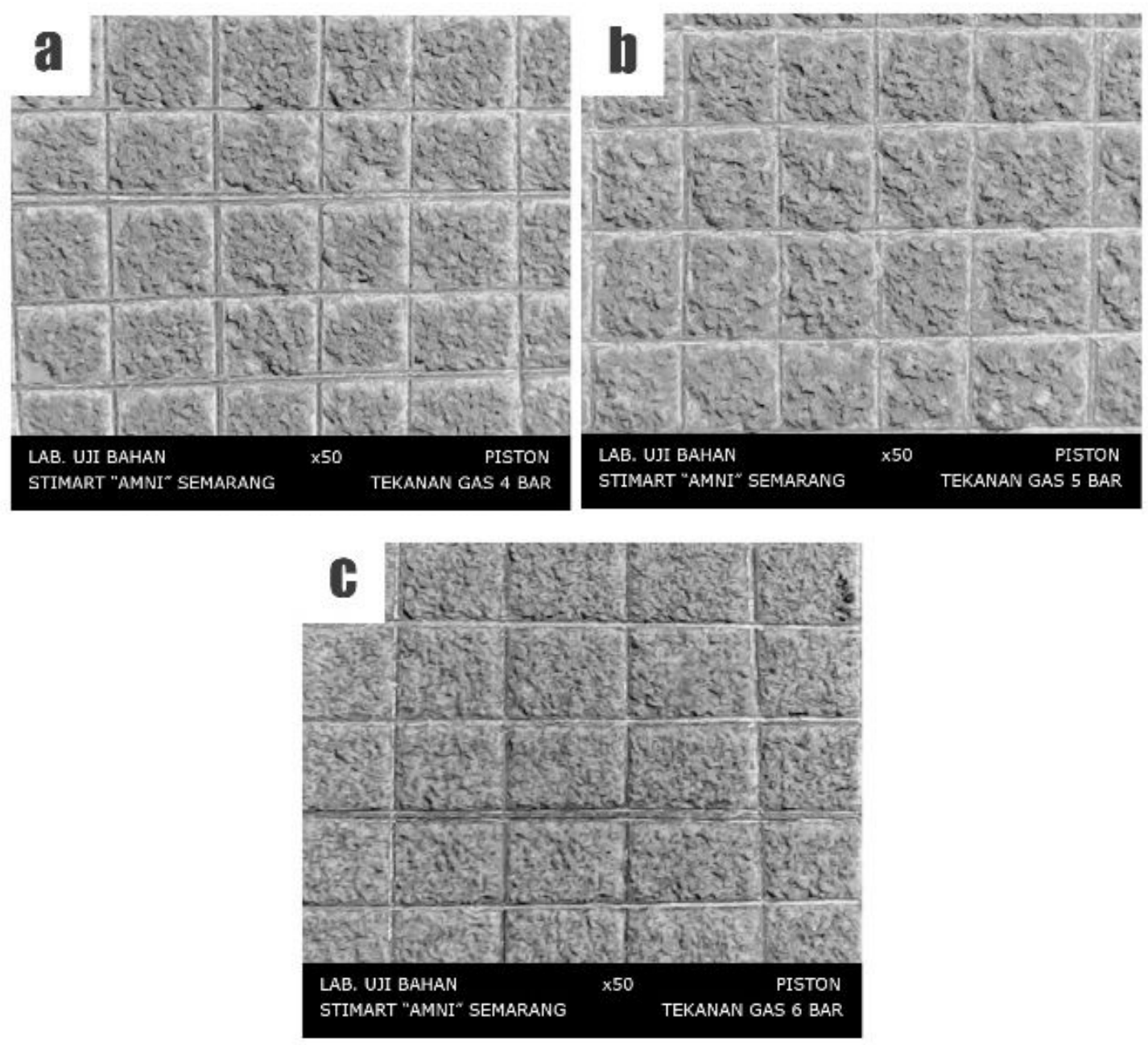

Gambar 5 Hasil Uji Kerekatan

(A) 4 Bar, (B) 5 Bar, (C) 6 Bar

Pengujian kerekatan pada spesimen dengan variabel tekanan oksigen 4 bar, tekanan oksigen 5 bar dan tekanan oksigen 6 bar didapatkan hasil pada Tabel 1. Untuk nilai rating dan presentasenya berdasarkan standar ASTM D 3395-09 mengenai uji kerekatan.

Tabel 1. Hasil Pengujian Kerekatan

\begin{tabular}{|c|c|c|c|c|c|c|c|}
\hline \multirow{2}{*}{ No. } & \multirow{2}{*}{ Specimen } & \multicolumn{3}{|c|}{ Rating Number } & \multicolumn{3}{c|}{ Presentase (\%) } \\
\cline { 3 - 8 } & & I & II & III & I & II & III \\
\hline 1. & Piston Tekanan Gas $\mathrm{O}_{2} 4 \mathrm{Bar}$ & $2 \mathrm{~B}$ & $2 \mathrm{~B}$ & $2 \mathrm{~B}$ & $18 \%$ & $16 \%$ & $19 \%$ \\
\hline 2. & Piston Tekanan $\mathrm{Gas} \mathrm{O}_{2} 5 \mathrm{Bar}$ & $3 \mathrm{~B}$ & $3 \mathrm{~B}$ & $3 \mathrm{~B}$ & $6 \%$ & $5 \%$ & $7 \%$ \\
\hline 3. & Piston Tekanan Gas $\mathrm{O}_{2} 6 \mathrm{Bar}$ & $4 \mathrm{~B}$ & $4 \mathrm{~B}$ & $4 \mathrm{~B}$ & $4 \%$ & $4 \%$ & $3 \%$ \\
\hline
\end{tabular}


Pengembangan sistem thermal barier coating modern saat ini, menitik beratkan pada bagaimana menghasilkan lapisan bond coat yang mampu membentuk lapisan protektif secara alami, kontinu dan perlahan (slow growing) dengan ketebalan tertentu, seragam dan memiliki daya ikat yang optimal guna menghindari terjadinya kegagalan dini (spallation) (Heuer A. H., dkk., 2006).

Berdasarkan hasil uji ketiga specimen menunjukkan bahwa pelapisan pada tekanan oksigen 6 Bar mempunyai adhesive yang paling bagus dibandingkan dengan spesimen pada tekanan oksigen 4 Bar dan 5 Bar. Penyebabnya adalah tekanan oksigen 6 Bar serbuk hidroxyapatite lebih menyatu dan menghasilkan ikatan yang terbaik dibandingkan dengan tekanan oksigen 4 Bar dan 5 Bar. Selain itu, pada penelitian yang lain dijelaskan bahwa porositas dalam jumlah yang rendah dapat memperbaiki sifat kerapatan coating dan menghasilkan ikatan yang baik antara substrat dengan lapisan coating. Besarnya tingkat porositas meningkatkan rongga permukaan antara coating dengan substrat sehingga menurunkan tingkat kelekatan antara permukaan substrat dengan lapisan coating (Suchaimi M, dkk, 2017).

\section{Uji Konduktivitas Panas}

Pengujian konduktifitas thermal ini dimaksudkan untuk mengetahui pengaruh hasil lapisan terhadap panas. Dengan memperhatikan waktu, suhu dan ketebalan lapisan. Spesimen pertama dengan 4 kali lapis / 4 Bar, spesimen kedua 4 kali lapis / 5 Bar, spesimen ketiga 4 kali lapis / 6 Bar. Pengujian konduktifitas thermal ini menggunakan standar ASTM C 177-1997 menggunakan less method. Dimana data yang diperoleh perbedaan suhu bagian atas yang dilapisi dengan bagian bawah yang tidak dilapisi. Waktu yang ditentukan 20 second. Berikut adalah hasil uji seperti pada Tabel 2.

Tabel 2 Data Temperatur Hasil Pengujian Konduktivitas Thermal

\begin{tabular}{|c|c|c|c|c|}
\hline & T1 & T2 & T3 & Time \\
\hline tanpa lapisan & 78 & 72 & & 20 \\
\hline 4 Bar & 78 & 71 & 66 & 20 \\
\hline 5 Bar & 78 & 69 & 60 & 20 \\
\hline 6 Bar & 78 & 68 & 56 & 20 \\
\hline
\end{tabular}


Berdasarkan penghitungan untuk mencari konduktifitas thermal dari berbagai ketebalan lapisan diperoleh nilai $\mathrm{kb}_{1}=0,4034 \mathrm{cal} / \mathrm{msK}, \mathrm{kb}_{2}=0,2594 \mathrm{cal} / \mathrm{msK}$ dan $\mathrm{Kb}_{3}=0,2212$ $\mathrm{cal} / \mathrm{msK}$. Sehingga dapat dirata - rata nilai kb hydroxyapatite adalah 0,295 cal/msK. Data suhu diatas dapat dicari resistant dari pelapisan yang digunakan. Berdasarkan rumus perambatan menggunakan analogi listrik bahan yang disusun secara seri sebagai berikut :

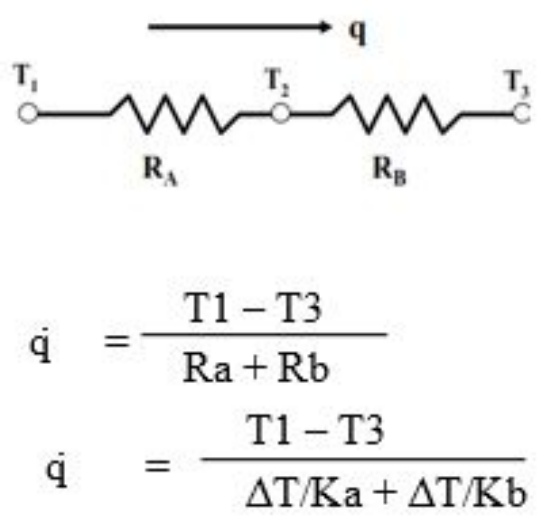

Berdasarkan rumus tersebut resistant yang terjadi pada piston dan hydroxyapatite dijumlahkan karena tersusun seri. Dari penghitungan tersebut diperoleh resistant pada spesimen pertama $9,8445 \mathrm{~K} / \mathrm{w}$, spesimen kedua $14,7667 \mathrm{~K} / \mathrm{w}$ dan spesimen ketiga 18,0482 $\mathrm{K} /$ w. Gambar 6 adalah grafik resistant thermal yang terbentuk.

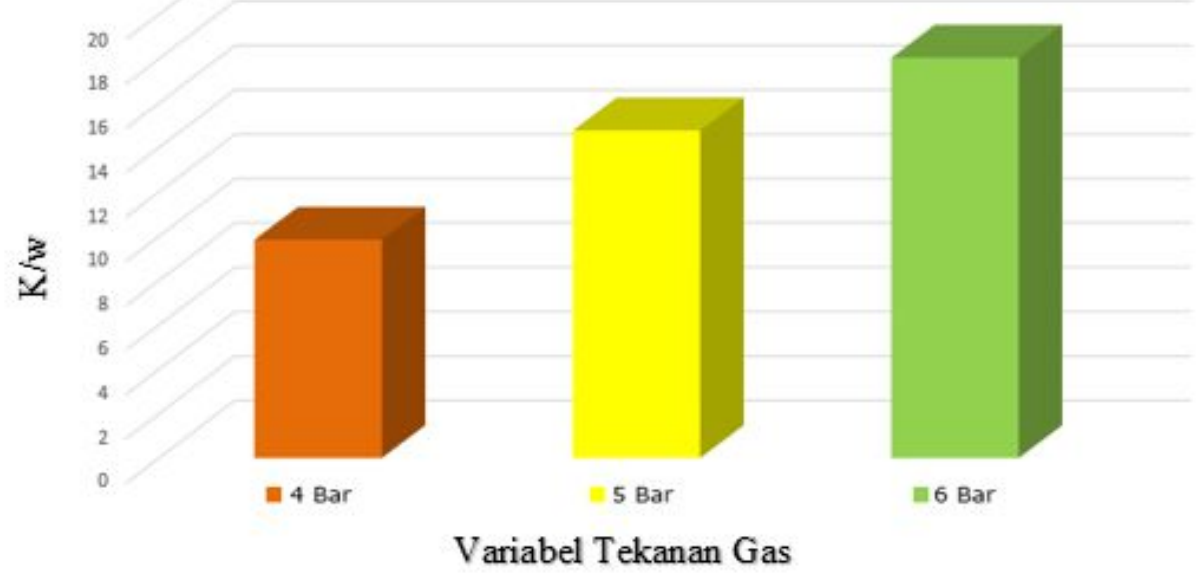

Gambar 6. Grafik Resistant Thermal

Semakin besar volume partikel semakin besar resistant yang ditimbulkan karena volume ini menghalangi panas yang masuk ke material (Pringgo, 2014). Berdasarkan data tabel dan hitungan resistant dapat dianalisa bahwa semakin tebal lapisan yang terbentuk 
semakin besar juga resistant yang ditimbulkan untuk menghalangi panas yang masuk ke substrat.

\section{KESIMPULAN}

Berdasarkan penelitian yang telah dilakukan dapat ditarik kesimpulan sebagai berikut :

1. Pelapisan menggunakan hydroxyapatite pada tekanan gas oksigen 6 Bar dengan ketebalan pelapis $250 \mu \mathrm{m}$ mempunyai morfologi yang lebih homogen, tingkat kerekatan yang lebih baik dengan kerusakan lapisan sekitar 4\% dan nilai rating termasuk dalam kategori 4B, terjadi difusi permukaan secara merata dibandingkan dengan spesimen pelapisan dengan tekanan gas oksigen 4 Bar dan 5 Bar.

2. Pelapis menggunakan hydroxyapatite dengan tekanan gas oksigen 6 Bar dengan ketebalan pelapis $250 \mu \mathrm{m}$ didapat nilai konduktivitas thermal dari hydroxyapatite yaitu sebesar, $\mathrm{K}_{\mathrm{HA}}=0,295 \mathrm{cal} / \mathrm{msK}$.

\section{DAFTAR PUSTAKA}

ASTM C 177 - 1997 Standart uji Konduktifitas thermal.

ASTM D 3359 - 02, 2007 Standard Test Methods for Measuring Adhesion by Tape Test.

ASTM F 1372 - 93 (Reapproved 2005) Standard Test Method forScanning Electron Microscope (SEM) Analysis of MetallicSurface Condition for Gas Distribution System Components.

Budinski. 2001. Engineering Material Properties and Selection. PHI New Delhi, pp. 517-536 Liem Benny, Suhu Mesin Mobil Bisa 250 Derajat. Di akses pada tanggal 5 Oktober 2017. https://www.otosia.com.

Lusiani R., Sunardi, Hamidi, (2013), Sifat Mekanik Lapisan Stainless Steel 316 pada Baja Karbon Rendah dengan Proses Electric Arc Spray, Prosiding Seminar Nasional Industrial Services (SNIS) III, Cilegon 13 Oktober 2013.

M Dileep, Sanjay Patel Sunny, Mandloi R. K. Alalytical Study of Fatigue of Aluminium Alloy Piston in IC Engines, IRJET Volume 03 Issues 04 April 2016.

Manohar Baalaganapathy, Jothl Miller, R Udaykumar, 2016 The Effects of Thermal Barrier Coating on Thermal Stress and Temperature Distribution in a Diesel Engine Piston for Magnesia/Yittria Partially Stabliliszed Zirconia, IJRMET Vol. 6, Issue 1, Nov 2015April 2016. 
Paulussen, S; Rego, R; Goossens, O; Vangeneugden, D; Rose, K, 2005, "Plasma polymerization of hybrid organic-inorganic monomers in an atmospheric pressure dielectric barrier discharge". Surface and Coatings Technology. 200: 672.

Pratama, Putu Ditha. 2017. Pengaruh Tekanan Gas Terhadap Sifat Mekanik dan Morfologi, Lapisan Coating Pencampuran FeCrBMnSi dan NiAl pada Baja AISI 4140 dengan Metode Twin Wire Arc Spray. ITS

Raftsan Zani. 2015. www.raftquality.blogspot.co.id. Thermal Spray, diakses pada 15 Juli 2017.

Sankar Vishnu. Thermal Barrier Coating Material Selection, Method of Preparation and Applications. IJMEER Vol 3 No. 2 April 2014.

Tong W, Chen J, Li X, Cao Y, Yang Z, Feng J, Zhang X. 1996. "Effect of particle size on molten states of starting powder and degradation of the relevant plasma-sprayed hydroxyapatite coatings".Biomaterials;17:1507-1513.

www.jepistons.com, Piston Terminology, , diakses tanggal 14 Januari 2015.

\section{PENULIS:}

\section{DEVOUT PRAKOSO TRISMIANTO}

Program Studi Teknik Mesin Fakultas Teknik

Universitas Muhammadiyah Semarang

Email : devout.prakoso@gmail.com 